\title{
Protein chemical identification and characterization of the human variants of far upstream element binding protein in medulloblastoma DAOY cell line
}

\author{
EPHREM ENGIDAWORK ${ }^{1,2}$, LEILA AFJEHI-SADAT ${ }^{1}$, JAE-WON YANG $^{1}$, IRENE SLAVC $^{1}$ and GERT LUBEC ${ }^{1}$ \\ ${ }^{1}$ Department of Pediatrics, Medical University of Vienna, Waehringer Guertel 18-20, A-1090, Vienna, Austria; \\ ${ }^{2}$ Department of Pharmacology, School of Pharmacy, Addis Ababa University, Addis Ababa, Ethiopia
}

Received January 27, 2006; Accepted March 30, 2006

\begin{abstract}
The assembly of trans-acting proteins on sequencespecific DNA cis-elements is crucial in the regulation of eukaryotic gene expression. Far upstream element binding proteins $(\mathrm{FAB})$ are proteins that regulate the expression of the $\mathrm{c}-m y c$ oncogene by binding to the far upstream element of the c-myc gene. The present study unambiguously identified the two human variants of FAB (FAB1, FAB2) in the medulloblastoma DAOY cell line and characterized their structure for the first time by tandem mass spectrometry independent of antibody availability and specificity. The study also tentatively assigned the third variant (FAB3) at the level of mass spectrometry, although tandem mass spectrometric analysis failed to corroborate the result. These findings open up an exciting possibility for discerning the cellular roles of FAB in tumor biology.
\end{abstract}

\section{Introduction}

In addition to conventional transcription factors bearing DNA binding and effector domains, several sequencespecific single-stranded DNA-binding proteins have been suggested to regulate gene expression (1). Among these, far upstream element (FUSE)-binding proteins (FBP) comprise a family of homologous gene regulatory proteins capable of tethering a powerful activation motif to specific sequences in single-stranded DNA (2-4). So far, three variants are known in humans (FBP1, FBP2 and FBP3), which have three distinct functional domains that display strong primary sequence and predicted secondary structure homology. The

Correspondence to: Professor Gert Lubec, Department of Pediatrics, Division of Basic Sciences, Medical University of Vienna, Waehringer Guertel 18-20, A-1090, Vienna, Austria

E-mail: gert.lubec@meduniwien.ac.at

Key words: medulloblastoma, DAOY cell line, far upstream element binding protein, mass spectrometry, tandem mass spectrometry, two dimensional electrophoresis
$\mathrm{N}$-terminus domain represses transcription in cis and in trans. By contrast, the C-terminus domain confers transactivation through multiple repeats of a powerful tyrosine-rich activation motif. The central domain binds single-stranded nucleic acids of specific sequences and is composed of four distinct $\mathrm{K}$ homology $(\mathrm{KH})$ motifs, each followed by an amphipathic helix (3-5).

Medulloblastoma is the most frequent malignant brain tumor in children and is considered to be of neuroectodermal origin. The medulloblastoma precursor cells are bipotential, able to differentiate into neuronal or glial cell types depending on stimulatory signals from the environment (6). Two main representative cell lines, DAOY and D283, are widely used in studies of medulloblastoma, as they show expression of glial and neuronal elements. In an attempt to identify novel and known proteins that could serve as candidate markers and/or therapeutic targets for medulloblastoma, we generated proteome maps of both cell lines, consisting of a series of proteins already linked to malignancy (7). In the present study, we analyzed the DAOY cell line, as it expresses both neuronal and glial elements, by two dimensional gel electrophoresis (2-DE) coupled to matrix-assisted laser desorption/ionization (MALDI) mass spectroscopy (MS) followed by tandem mass spectroscopy (MS/MS) because the specificity of MS/MS-based protein identification is much higher than that of MS (8). We report for the first time expression of all three variants of human FBPs at the protein level in the DAOY cell line.

\section{Materials and methods}

Cell culture and sample preparation. The DAOY cell line [ATCC: HTB-186; (9)] was cultivated according to specific ATCC guidelines (http://www.lgcpromochem-atcc.com/ SearchCatalogs/lor). Harvested cells were washed three times with $10 \mathrm{ml}$ PBS (phosphate-buffered saline) (Gibco BRL, Gaithersburg, MD, USA) and centrifuged for $10 \mathrm{~min}$ at $800 \mathrm{x} \mathrm{g}$ at room temperature. The supernatant was discarded and the pellet was suspended in $1.0 \mathrm{ml}$ of sample buffer consisting of $40 \mathrm{mM}$ Tris, $7 \mathrm{M}$ urea (Merck, Darmstadt, Germany), $2 \mathrm{M}$ thiourea (Sigma, St. Louis, MO, USA), 4\% CHAPS (3-[(3cholamidopropyl)dimethylammonio]-1-propane-sulfonate) (Sigma), 65 mM 1,4-dithioerythritol (Merck), 1 mM EDTA (ethylenediaminetetraacetic acid) (Merck), protease inhibitors 
complete $^{\circledR}$ (Roche, Basel, Switzerland) and $1 \mathrm{mM}$ phenylmethylsulfonyl fluoride. The suspension was sonicated for $\sim 30 \mathrm{sec}$. After homogenization, samples were left at room temperature for $1 \mathrm{~h}$ and centrifuged at $14,000 \mathrm{rpm}$ for $1 \mathrm{~h}$. The supernatant was transferred into Ultrafree- 4 centrifugal filter units (Millipore, Bedford, MA) for desalting and concentrating proteins. The protein content of the supernatant was quantified by the Bradford protein assay (10). The standard curve was generated using bovine serum albumin and absorbance was measured at $595 \mathrm{~nm}$.

Two-dimensional gel electrophoresis (2-DE). 2-DE was performed in triplicate as reported elsewhere (11). Protein $(500 \mu \mathrm{g})$ was applied on immobilized $\mathrm{pH}$ 3.0-10.0 non-linear gradient strips in sample cups at their basic and acidic ends. Focusing was started at $200 \mathrm{~V}$ and the voltage was gradually increased to $5000 \mathrm{~V}$ at a rate of $3 \mathrm{~V} / \mathrm{min}$ and then kept constant for a further $24 \mathrm{~h}(\sim 180,000 \mathrm{Vh}$ in total). After the first dimension, strips $(18 \mathrm{~cm})$ were equilibrated for $15 \mathrm{~min}$ in the buffer containing $6 \mathrm{M}$ urea, $20 \%$ glycerol, $2 \%$ SDS and $2 \%$ 1,4-dithioerythritol and then for $15 \mathrm{~min}$ in the same buffer containing $2.5 \%$ iodoacetamide instead of 1,4dithioerythritol. After equilibration, strips were loaded on 9-16\% gradient SDS gels for second-dimensional separation. Gels $(180 \times 200 \times 1.5 \mathrm{~mm})$ were then run at $40 \mathrm{~mA}$ per gel. Immediately after the second dimension run, gels were fixed for $18 \mathrm{~h}$ in $50 \%$ methanol, containing $10 \%$ acetic acid, the gels were then stained with Colloidal Coomassie Blue (Novex, San Diego, CA) for $12 \mathrm{~h}$ on a rocking shaker. Molecular masses were determined by running standard protein markers (Bio-Rad Laboratories, Hercules, CA) covering the range of $10-250 \mathrm{kDa}$. pI values were used as given by the supplier of the immobilized $\mathrm{pH}$ gradient strips (Amersham Bioscience, Uppsala, Sweden). Excess of dye was washed out from the gels with distilled water and the gels were scanned with ImageScanner (Amersham Bioscience). Electronic images of the gels were recorded using Adobe Photoshop and Microsoft Power Point software.

Matrix-assisted laser desorption/ionization mass spectroscopy/ mass spectroscopy (MALDI/MS/MS). Spots were excised with a spot picker (Proteineer $\mathrm{sp}^{\mathrm{TM}}$, Bruker Daltonics, Germany) and placed into a 384-well microtiter plate. In-gel digestion and sample preparation for MALDI analysis were performed by an automated procedure (Proteineer $\mathrm{dp}^{\mathrm{TM}}$, Bruker Daltonics) (12). Briefly, spots were excised and washed with $10 \mathrm{mM}$ ammonium bicarbonate and $50 \%$ acetonitrile in $10 \mathrm{mM}$ ammonium bicarbonate. After washing, gel plugs were shrunk by addition of acetonitrile and dried by blowing out the liquid through the pierced well bottom. The dried gel pieces were re-swollen with $40 \mathrm{ng} / \mu \mathrm{l}$ trypsin (Promega, Madison, USA) in enzyme buffer (consisting of $5 \mathrm{mM}$ octyl B-D-glucopyranoside and $10 \mathrm{mM}$ ammonium bicarbonate) and incubated for $4 \mathrm{~h}$ at $30^{\circ} \mathrm{C}$. Peptide extraction was performed with $10 \mu \mathrm{l}$ of $1 \%$ trifluoroacetic acid in $5 \mathrm{mM}$ octyl $\mathrm{B}$-D-glucopyranoside. Extracted peptides were directly applied onto a target (AnchorChip $^{\mathrm{TM}}$, Bruker Daltonics) that was loaded with $\alpha-$ cyano-4-hydroxy-cinnamic acid (Bruker Daltonics) matrix thinlayer. The mass spectrometer used in this work was an Ultraflex $^{\mathrm{TM}}$ TOF/TOF (Bruker Daltonics) operated in the reflector mode for MALDI-TOF peptide mass fingerprint (PMF) or LIFT mode for MALDI-TOF/TOF with a fully automated mode using FlexControl ${ }^{\mathrm{TM}}$ software. An accelerating voltage of $25 \mathrm{kV}$ was used for PMF. Calibration of the instrument was performed externally with $[\mathrm{M}+\mathrm{H}]^{+}$ions of angiotensin I, angiotensin II, substance P, bombesin, and adrenocorticotropic hormones (clip 1-17 and clip 18-39). Each spectrum was produced by accumulating data from 200 consecutive laser shots. Those samples which were analyzed by PMF from MALDI-TOF were additionally analyzed using LIFT-TOF/TOF MS/MS from the same target. A maximum of three precursor ions per sample were chosen for MS/MS analysis. In the TOF1 stage, all ions were accelerated to $8 \mathrm{kV}$ under conditions promoting metastable fragmentation. After selection of jointly migrating parent and fragment ions in a timed ion gate, ions were lifted by $19 \mathrm{kV}$ to high potential energy in the LIFT cell. After further acceleration of the fragment ions in the second ion source, their masses could be simultaneously analyzed in the reflector with high sensitivity. PMF and LIFT spectra were interpreted with Mascot software (Matrix Science Ltd., London, UK). Database searches, through Mascot, using combined PMF and MS/MS datasets were performed via BioTools 2.2 software (Bruker). A mass tolerance of $25 \mathrm{ppm}$ and 1 missing cleavage site for PMF and MS/MS tolerance of $0.5 \mathrm{Da}$ were allowed and oxidation of methionine residues was considered. The probability score calculated by the software was used as criterion for correct identification. The algorithm used for the determination of the probability of a false positive match with a given mass spectrum is described elsewhere (13).

\section{Results}

2-DE coupled to MALDI/MS/MS was used to analyze the expression of the DAOY medulloblastoma cell line in an attempt to elucidate marker proteins and identified an interesting protein family, FBP, that is relevant to tumor biology. 2-DE analysis of the DAOY medulloblastoma cell line revealed a total of eight spots, of which two spots represented FBP1, five spots represented FBP2 and one spot represented FBP3 (Fig. 1) with theoretical pI range of 7.2-8.0, and theoretical molecular weight range of $67-73 \mathrm{kDa}$ (Table I). For the purpose of simplicity, the two spots of FBP1 are designated as FBP1a and FBP1b (a, b from left to right in Fig. 1) and that of FBP2 as FBP2a-e (d, c, b, a, e from left to right). There appeared to be a shift in observed $\mathrm{pI}$ as well as molecular weight from the theoretical values. Whilst a decreasing trend was noted in observed pI, molecular weight was increased for all spots of different variants of FBPs (Table I).

Subjecting the spots to PMF followed by MS/MS analysis produced significant MS/MS results for the two identified spots of FBP1. Data obtained from MS analysis are summarized in Table I. As shown in Table I, whilst PMF analysis of the spot of FBP1a revealed sequence coverage of $45 \%$, that of FBP1b showed 43\% (Fig. 2a). Following identification by PMF, the workflow control software automatically selected two peaks for FBP1a (m/z 1336.74 and $\mathrm{m} / \mathrm{z} 1539.81)$ and three peaks (m/z 931.56, m/z 1336.72 and m/z 1539.80) for FBP1b (Fig. 3a and b) from the MS spectrum to generate 
$\omega$

A

б용.

क

造

总.

芯迹

¿

苍.

完票

言產

芯
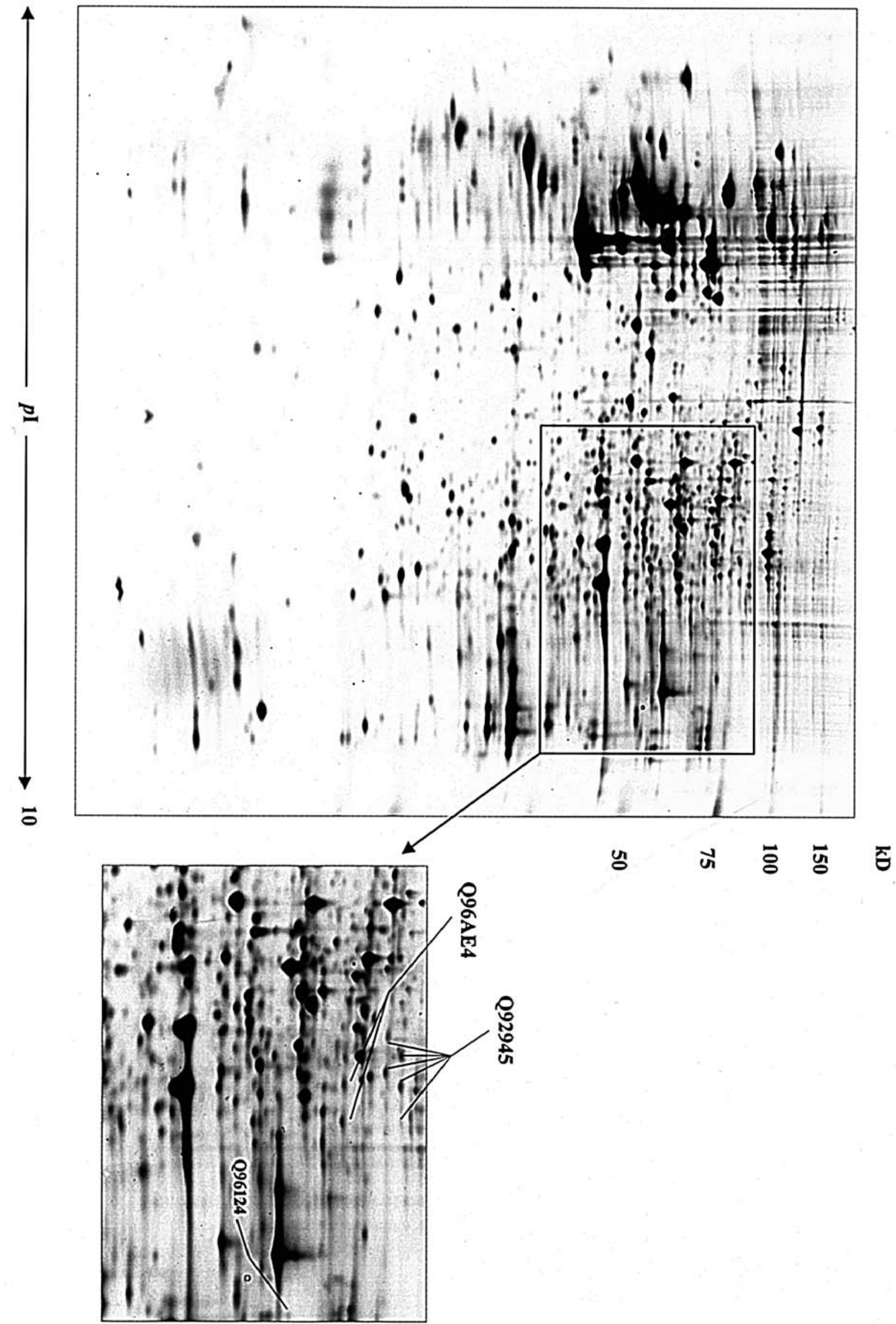


\section{a. Upper panel for FBP1a and lower panel for FBP1b}

MADYSTVPPP SSGSAGGGGG GGGGGGVNDA FKDALQRARQ IAAKIGGDAG TSLNSNDYGY GGQKRPLEDG DQPDAKKVAP QNDSFGTQLP PMHQQQRSVM TEEYKVPDGM VGFIIGRGGE QISRIQQESG CKIQIAPDSG GLPERSCMLT GTPESVQSAK RLLDQIVEKG RPAPGFHHGD GPGNAVQEIM IPASKAGLVI GKGGETIKQL QERAGVKMVM IQDGPQNTGA DKPLRITGDP YKVQQAKEMV LELIRDQGGF REVRNEYGSR IGGNEGIDVP IPRFAVGIVI GRNGEMIKKI QNDAGVRIQF KPDDGTTPER IAQITGPPDR CQHAAEIITD LLRSVQAGNP GGPGPGGRGR GRGQGNWNMG PPGGLQEFNF IVPTGKTGLI IGKGGETIKS ISQQSGARIE LQRNPPPNAD PNMKLFTIRG TPQQIDYARQ LIEEKIGGPV NPLGPPVPHG PHGVPGPHGP PGPPGPGTPM GPYNPAPYNP GPPGPAPHGP PAPYAPQGWG NAYPHWQQQA PPDPAKAGTD PNSAAWAAYY AHYYQQQAQP PPAAPAGAPT TTQTNGQGDQ QNPAPAGQVD YTKAWEEYYK KMGQAVPAPT GAPPGGQPDY SAAWAEYYRQ QAAYYAQTSP QGMPQHPPAP QGQ

MADYSTVPPP SSGSAGGGGG GGGGGGVNDA FKDALQRARQ IAAKIGGDAG TSLNSNDYGY GGQKRPLEDG DQPDAKKVAP QNDSFGTQLP PMHQQQRSVM TEEYKVPDGM VGFIIGRGGE QISRIQQESG CKIQIAPDSG GLPERSCMLT GTPESVQSAK RLLDQIVEKG RPAPGFHHGD GPGNAVQEIM IPASKAGLVI GKGGETIKQL QERAGVKMVM IQDGPQNTGA DKPLRITGDP YKVQQAKEMV LELIRDQGGF REVRNEYGSR IGGNEGIDVP IPRFAVGIVI GRNGEMIKKI QNDAGVRIQF KPDDGTTPER IAQITGPPDR CQHAAEIITD LLRSVQAGNP GGPGPGGRGR GRGQGNWNMG PPGGLQEFNF IVPTGKTGLI IGKGGETIKS ISQQSGARIE LQRNPPPNAD PNMKLFTIRG TPQQIDYARQ LIEEKIGGPV NPLGPPVPHG PHGVPGPHGP PGPPGPGTPM GPYNPAPYNP GPPGPAPHGP PAPYAPQGWG NAYPHWQQQA PPDPAKAGTD PNSAAWAAYY AHYYQQQAQP PPAAPAGAPT TTQTNGQGDQ QNPAPAGQVD YTKAWEEYYK KMGQAVPAPT GAPPGGQPDY SAAWAEYYRQ QAAYYAQTSP QGMPQHPPAP QGQ

b. matched peptides to FBP2a, FBP2b, FBP2c, FBP2d \& FBP2e

1 MSDYSTGGPP PGPPPPAGGG GGAGGAGGGP PPGPPGAGDR GGGPCGGGP 51 GGGSAGGPSQ PPGGGGPGIR KDAFADAVQR ARQIAAKIGG DAATTVNNST 101 PDFGFGGQKR QLEDGDQPES KKLASQGDSI SSQLGPIHPP PRTSMTEEYR 151 VPDGMVGLII GRGGEQINKI QQDSGCKVQI SPDSGGLPER SVSLTGAPES 201 VQKAKMMLDD IVSRGRGGPP GQFHDNANGG QNGTVQEIMI PAGKAGLVIG 251 KGGETIKQLQ ERAGVKMILI QDGSQNTNVD KPLRIIGDPY KVQQACEMVM 301 DILRERDQGG FGDRNEYGSR IGGGIDVPVP RHSVGWIGR SGEMIKKIQN 351 DAGVRIQFKQ DDGTGPEKIA HIMGPPDRCE HAARIINDLL QSLRSGPPGP 401 PGGPGMPPGG RGRGRGQGNW GPPGGEMTFS IPTHKCGLVI GRGGENVKAI

451 NQQTGAFVEI SRQLPPNGDP NFKLFIIRGS PQQIDHAKQL IEEKIEGPLC

501 PVGPGPGGPG PAGPMGPFNP GPFNQGPPGA PPHAGGPPPH QYPPQGWGNT 551 YPQWQPPAPH DPSKAAAAAA DPNAAWAAYY SHYYQQPPGP VPGPAPAPAA 601 PPAQGEPPQP PPTGQSDYTK AWEEYYKKIG QQPQQPGAPP QQDYTKAWEE 651 YYKKQAQVAT GGGPGAPPGS QPDYSAAWAE YYRQQAAYYG QTPGPGGPQP 701 PPTQQGQQQA Q

1 MSDYSTGGPP PGPPPPAGGG GGAGGAGGGP PPGPPGAGDR GGGPCGGGP 51 GGGSAGGPSQ PPGGGGPGIR KDAFADAVQR ARQIAAKIGG DAATTVNNST 101 PDFGFGGQKR QLEDGDQPES KKLASQGDSI SSQLGPIHPP PRTSMTEEYR 151 VPDGMVGLII GRGGEQINKI QQDSGCKVQI SPDSGGLPER SVSLTGAPES 201 VQKAKMMLDD IVSRGRGGPP GQFHDNANGG QNGTVQEIMI PAGKAGLVIG 251 KGGETIKQLQ ERAGVKMILI QDGSQNTNVD KPLRIIGDPY KVQQACEMVM 301 DILRERDQGG FGDRNEYGSR IGGGIDVPVP RHSVGVVIGR SGEMIKKIQN 351 DAGVRIQFKQ DDGTGPEKIA HIMGPPDRCE HAARIINDLL QSLRSGPPGP 401 PGGPGMPPGG RGRGRGQGNW GPPGGEMTFS IPTHKCGLVI GRGGENVKAI 451 NQQTGAFVEI SRQLPPNGDP NFKLFIIRGS PQQIDHAKQL IEEKIEGPLC 501 PVGPGPGGPG PAGPMGPFNP GPFNQGPPGA PPHAGGPPPH QYPPQGWGNT 551 YPQWQPPAPH DPSKAAAAAA DPNAAWAAYY SHYYQQPPGP VPGPAPAPAA 601 PPAQGEPPQP PPTGQSDYTK AWEEYYKKIG QQPQQPGAPP QQDYTKAWEE 651 YYKKQAQVAT GGGPGAPPGS QPDYSAAWAE YYRQQAAYYG QTPGPGGPQP 701 PPTQQGQQQA Q 
1 MSDYSTGGPP PGPPPPAGGG GGAGGAGGGP PPGPPGAGDR GGGGPCGGGP

51 GGGSAGGPSQ PPGGGGPGIR KDAFADAVQR ARQIAAKIGG DAATTVNNST

101 PDFGFGGQKR QLEDGDQPES KKLASQGDSI SSQLGPIHPP PRTSMTEEYR

151 VPDGMVGLII GRGGEQINKI QQDSGCKVQI SPDSGGLPER SVSLTGAPES

201 VQKAKMMLDD IVSRGRGGPP GQFHDNANGG QNGTVQEIMI PAGKAGLVIG

251 KGGETIKQLQ ERAGVKMILI QDGSQNTNVD KPLRIIGDPY KVQQACEMVM

301 DILRERDQGG FGDRNEYGSR IGGGIDVPVP RHSVGVVIGR SGEMIKKIQN

351 DAGVRIQFKQ DDGTGPEKIA HIMGPPDRCE HAARIINDLL QSLRSGPPGP

401 PGGPGMPPGG RGRGRGQGNW GPPGGEMTFS IPTHKCGLVI GRGGENVKAI

451 NQQTGAFVEI SRQLPPNGDP NFKLFIIRGS PQQIDHAKQL IEEKIEGPLC

501 PVGPGPGGPG PAGPMGPFNP GPFNQGPPGA PPHAGGPPPH QYPPQGWGNT

551 YPQWQPPAPH DPSKAAAAAA DPNAAWAAYY SHYYQQPPGP VPGPAPAPAA

601 PPAQGEPPQP PPTGQSDYTK AWEEYYKKIG QQPQQPGAPP QQDYTKAWEE

651 YYKKQAQVAT GGGPGAPPGS QPDYSAAWAE YYRQQAAYYG QTPGPGGPQP 701 PPTQQGQQQA Q

1 MSDYSTGGPP PGPPPPAGGG GGAGGAGGGP PPGPPGAGDR GGGGPCGGGP 51 GGGSAGGPSQ PPGGGGPGIR KDAFADAVQR ARQIAAKIGG DAATTVNNST 101 PDFGFGGQKR QLEDGDQPES KKLASQGDSI SSQLGPIHPP PRTSMTEEYR 151 VPDGMVGLII GRGGEQINKI QQDSGCKVQI SPDSGGLPER SVSLTGAPES 201 VQKAKMMLDD IVSRGRGGPP GQFHDNANGG QNGTVQEIMI PAGKAGLVIG 251 KGGETIKQLQ ERAGVKMILI QDGSQNTNVD KPLRIIGDPY KVQQACEMVM 301 DILRERDQGG FGDRNEYGSR IGGGIDVPVP RHSVGVVIGR SGEMIKKIQN 351 DAGVRIQFKQ DDGTGPEKIA HIMGPPDRCE HAARIINDLL QSLRSGPPGP 401 PGGPGMPPGG RGRGRGQGNW GPPGGEMTFS IPTHKCGLVI GRGGENVKAI 451 NQQTGAFVEI SRQLPPNGDP NFKLFIIRGS PQQIDHAKQL IEEKIEGPLC 501 PVGPGPGGPG PAGPMGPFNP GPFNQGPPGA PPHAGGPPPH QYPPQGWGNT 551 YPQWQPPAPH DPSKAAAAAA DPNAAWAAYY SHYYQQPPGP VPGPAPAPAA 601 PPAQGEPPQP PPTGQSDYTK AWEEYYKKIG QQPQQPGAPP QQDYTKAWEE 651 YYKKQAQVAT GGGPGAPPGS QPDYSAAWAE YYRQQAAYYG QTPGPGGPQP 701 PPTQQGQQQA Q

1 MSDYSTGGPP PGPPPPAGGG GGAGGAGGGPPPGPPGAGDRGGGGPCGGGP 51 GGGSAGGPSQ PPGGGGPGIR KDAFADAVQR ARQIAAKIGG DAATTVNNST 101 PDFGFGGQKR QLEDGDQPES KKLASQGDSI SSQLGPIHPP PRTSMTEEYR 151 VPDGMVGLII GRGGEQINKI QQDSGCKVQI SPDSGGLPER SVSLTGAPES 201 VQKAKMMLDD IVSRGRGGPP GQFHDNANGG QNGTVQEIMI PAGKAGLVIG 251 KGGETIKQLQ ERAGVKMILI QDGSQNTNVD KPLRIIGDPY KVQQACEMVM 301 DILRERDQGG FGDRNE YGSR IGGGIDVPVP RHSVGVVIGR SGEMIKKIQN 351 DAGVRIQFKQ DDGTGPEKIA HIMGPPDRCE HAARIINDLL QSLRSGPPGP 401 PGGPGMPPGG RGRGRGQGNW GPPGGEMTFS IPTHKCGLVI GRGGENVKAI 451 NQQTGAFVEI SRQLPPNGDP NFKLFIIRGS PQQIDHAKQL IEEKIEGPLC 501 PVGPGPGGPG PAGPMGPFNP GPFNQGPPGA PPHAGGPPPHQYPPQGWGNT 551 YPQWQPPAPH DPSKAAAAAA DPNAAWAAYY SHYYQQPPGP VPGPAPAPAA 601 PPAQGEPPQP PPTGQSDYTK AWEEYYKKIG QQPQQPGAPP QQDYTKAWEE 651 YYKKQAQVAT GGGPGAPPGS QPDYSAAWAE YYRQQAAYYG QTPGPGGPQP 701 PPTQQGQQQA Q

\section{c Matched peptides to FBP3}

1 MAELVQGQSA PVGMKAEGFV DAL.HRVRQIA AKIDSIPHLN NSTPLVDPSV 51 YGYGVQKRPL DDGVGNQLGA LVHQRTVITE EFKVPDKMVG FIIGRGGEQI 101 SRIQAESGCK IQIASESSGI PERPCVLTGT PESIEQAKRL LGQIVDRCRN 151 GPGFHNDIDS NSTIQEILIP ASKVGLVIGR GGETIKQLQE RTGVKMVMIQ 201 DGPLPTGADK PLRITGDAFK VQQAREMVLE IIREKDQADF RGVRGDFNSR 251 MGGGSIEVSV PRFAVGIVIG RNGEMIKKIQ NDAGVRIQFK PDDGISPERA 301 AQVMGPPDRC QHAAHIISEL ILTAQERDGF GGLAAARGRG RGRGDWSVGA 351 PGGVQEITYT VPADKCGLVI GKGGENIKSI NQQSGAHVEL QRNPPPNSDP 401 NLRRFTIRGV PQQIEVARQL. IDEKVGGTNL GAPGAFGQSP FSQPPAPPHQ 451 NTFPPRSSGC FPNMAAKVNG NPHSTPVSGP PAFLTQGWGS TYQAWQQPTQ 501 QVPSQQSQPQ SSQPNYSKAW EDYYKKQSHA ASAAPQASSP PDYTMAWAEY 551 YRQQVAFYGQ TLGQAQAHSQ EQ

Figure 2. Protein sequence of FBP with peptides matched (bold letters) demonstrating sequence coverage.

an MS/MS spectrum, as MS/MS analysis of one or more available peptides can provide unambiguous identification of a protein in question. Indeed, the generated LIFT-TOF/TOF spectra of m/z 1336.74 and m/z 1539.81 were significantly matched to peptide IGGNEGIDVPIPR and peptide CQHAA EIITDLLR, respectively (Fig. 3a). Likewise, the generated 

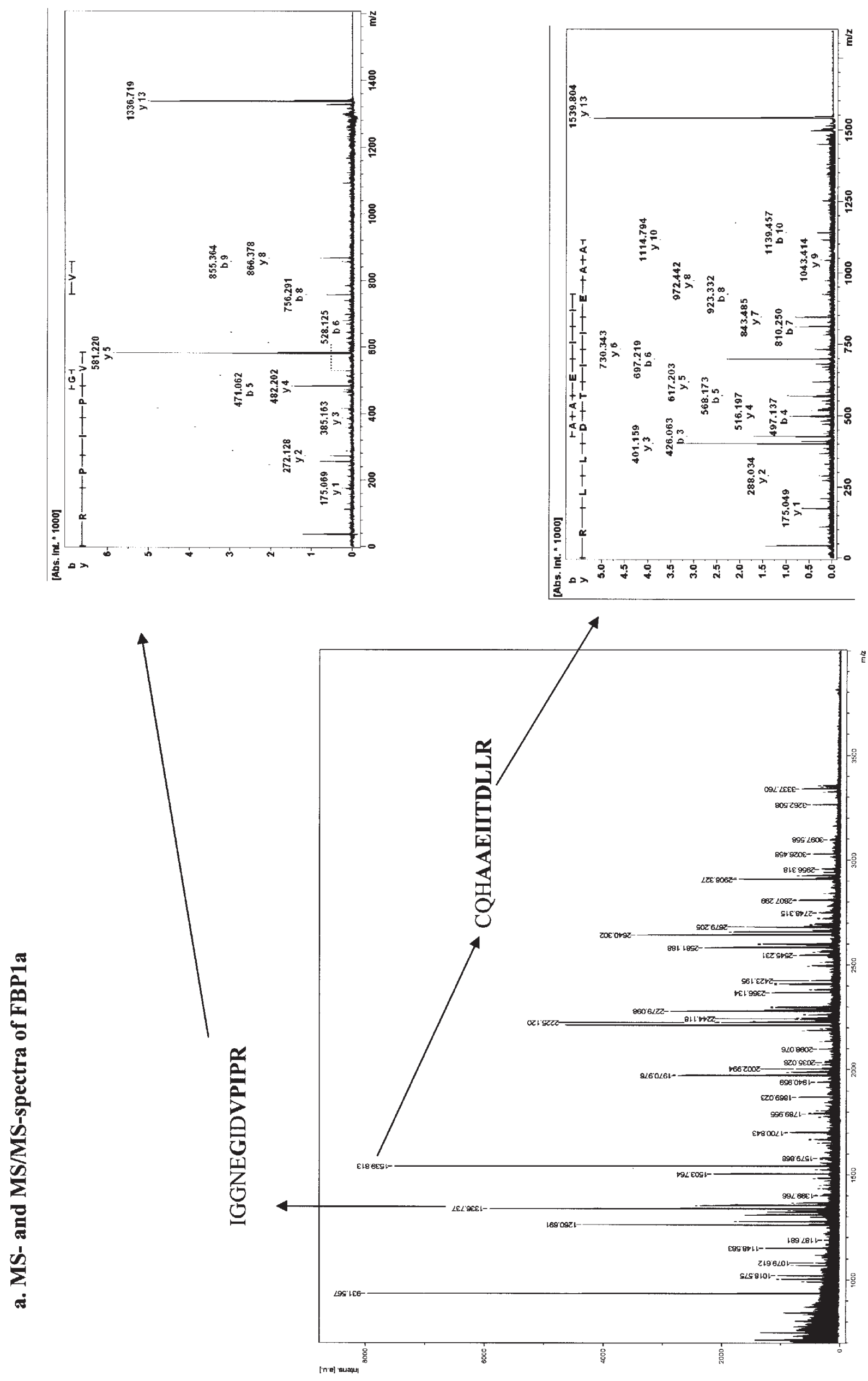

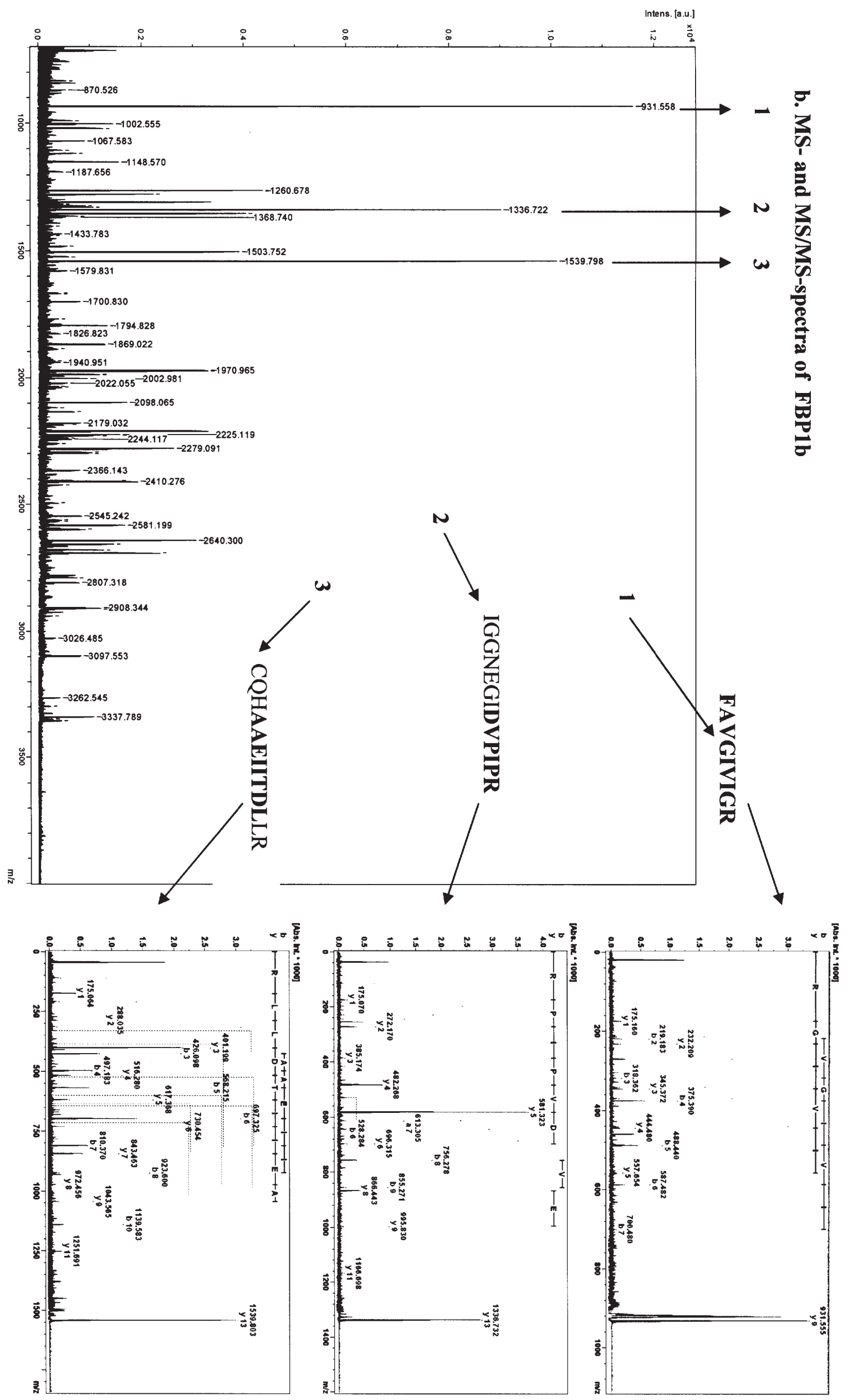


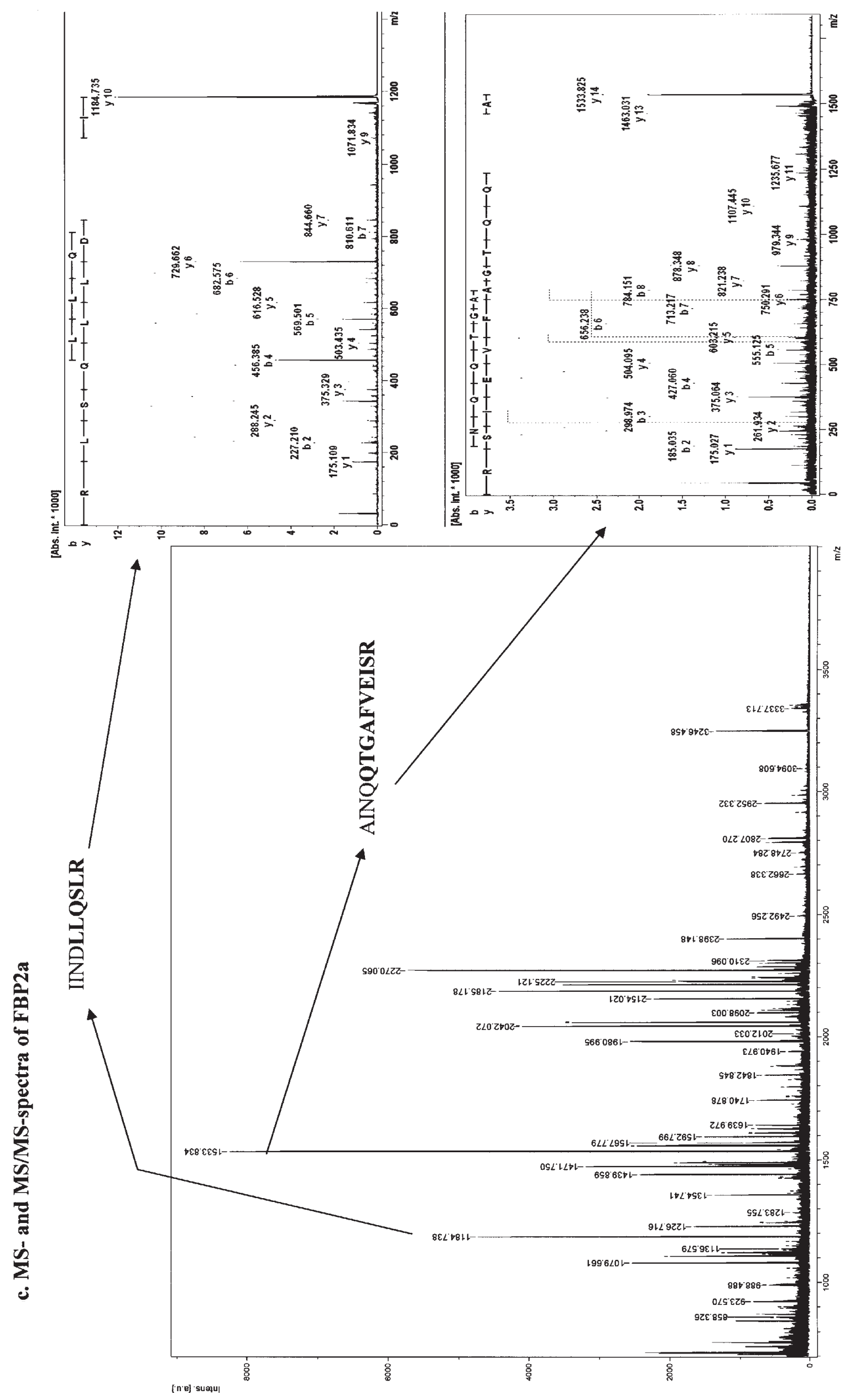




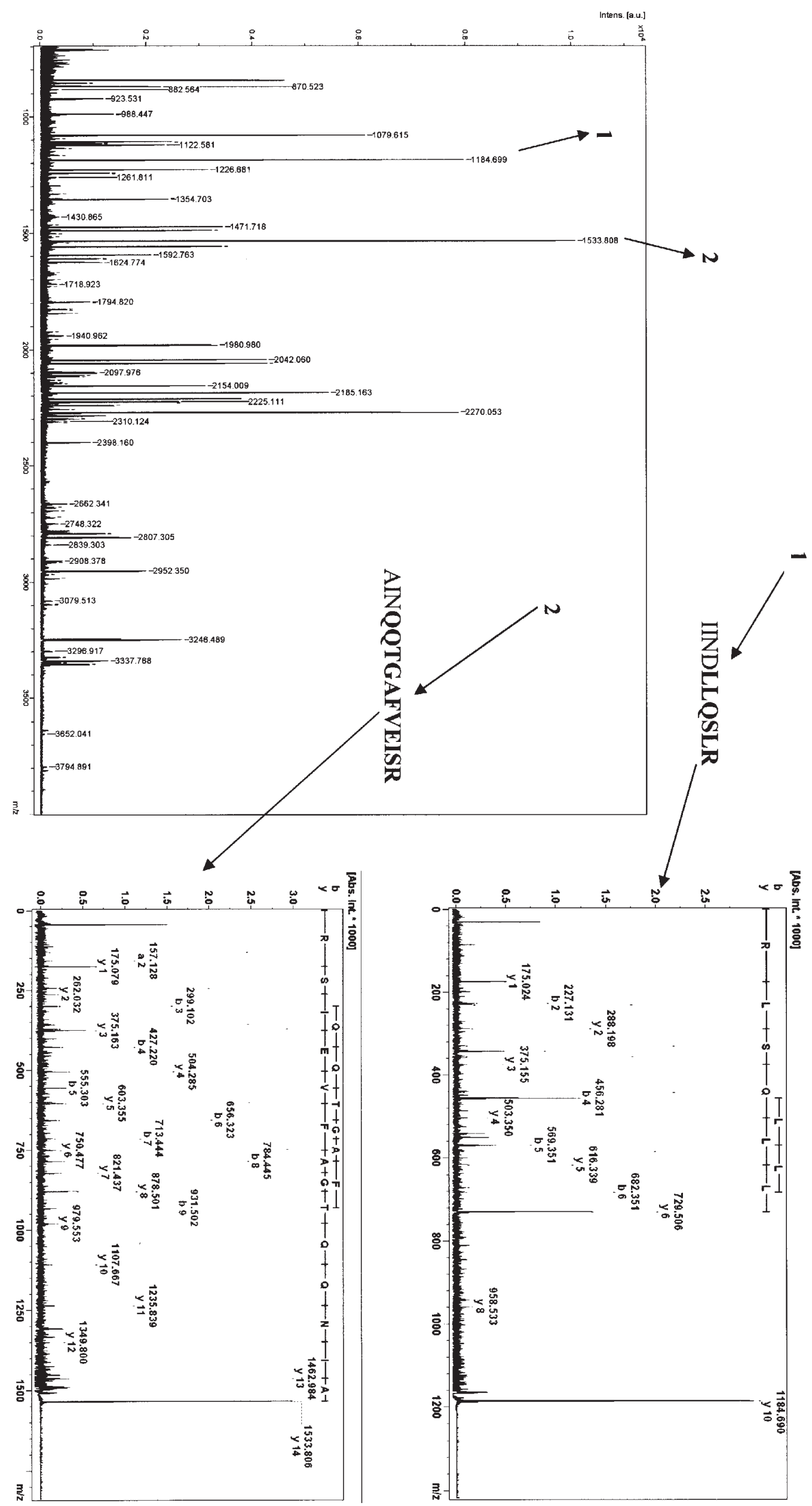




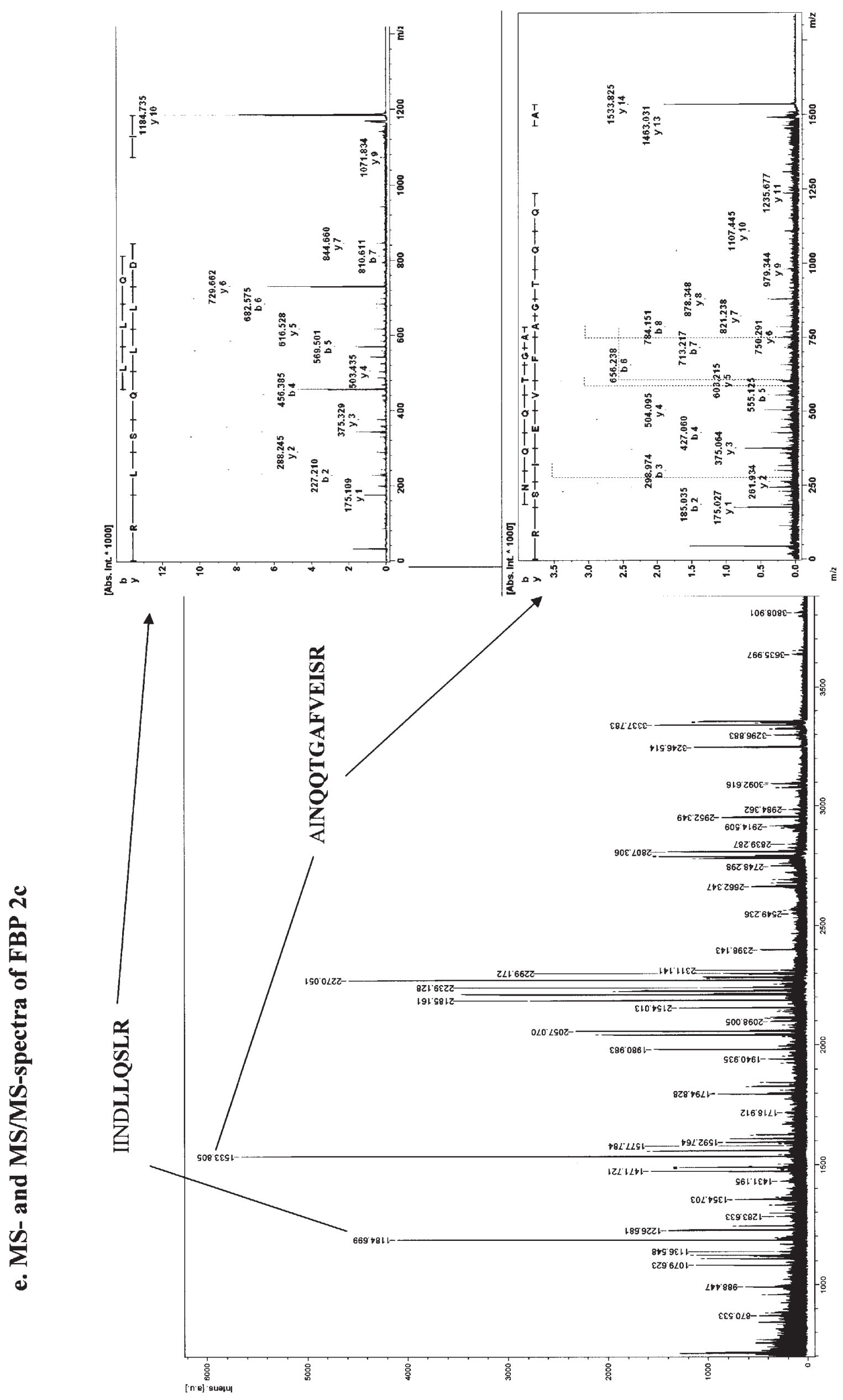




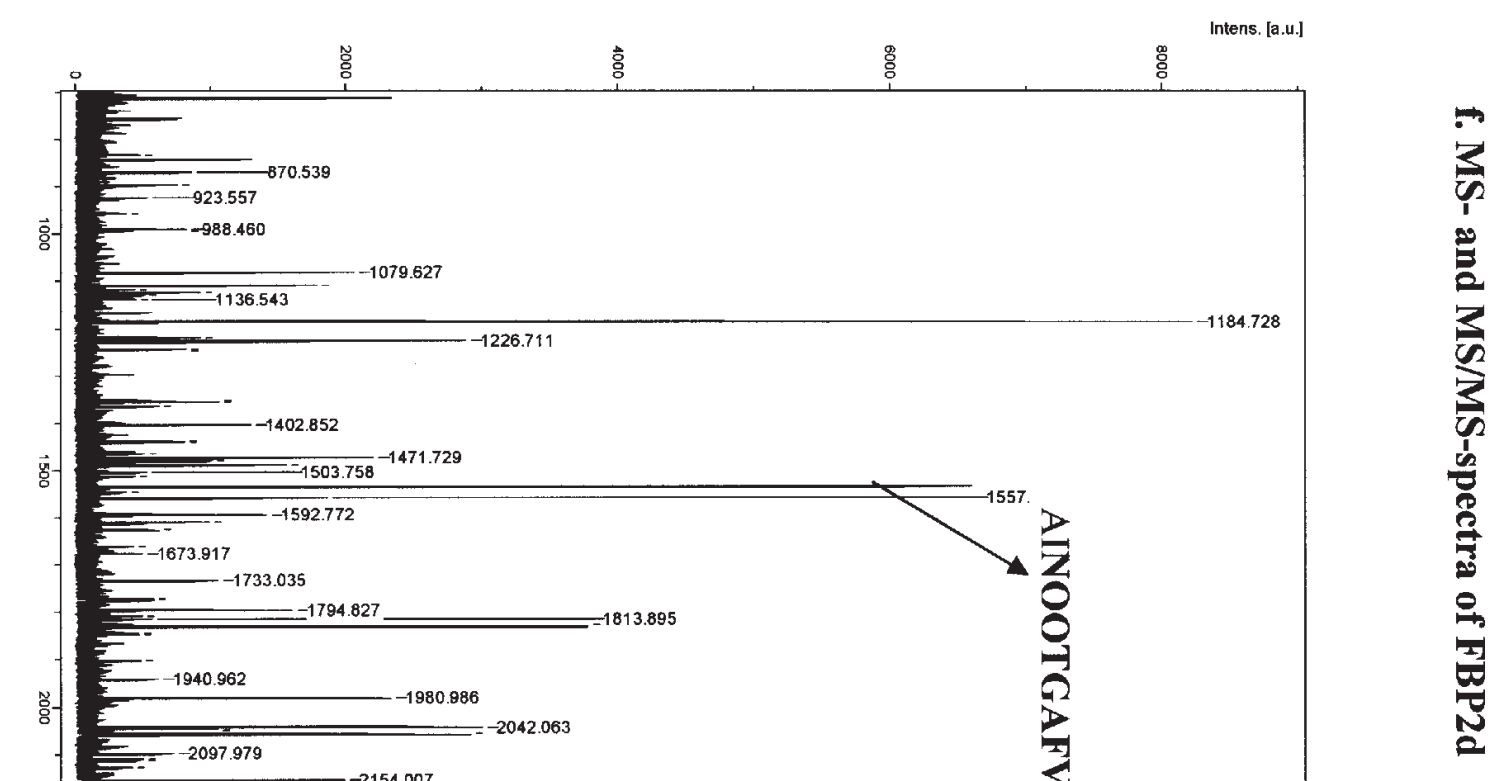




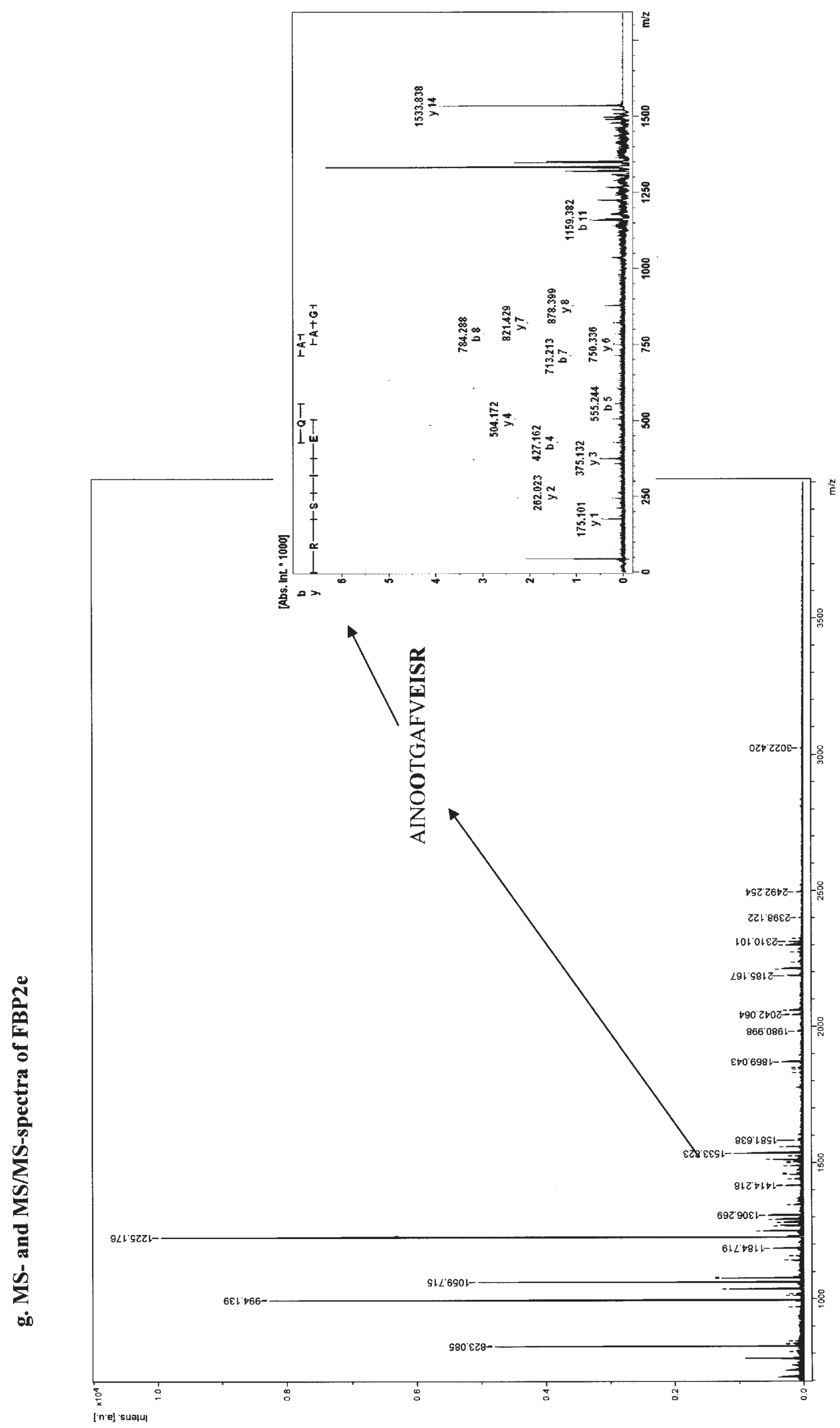




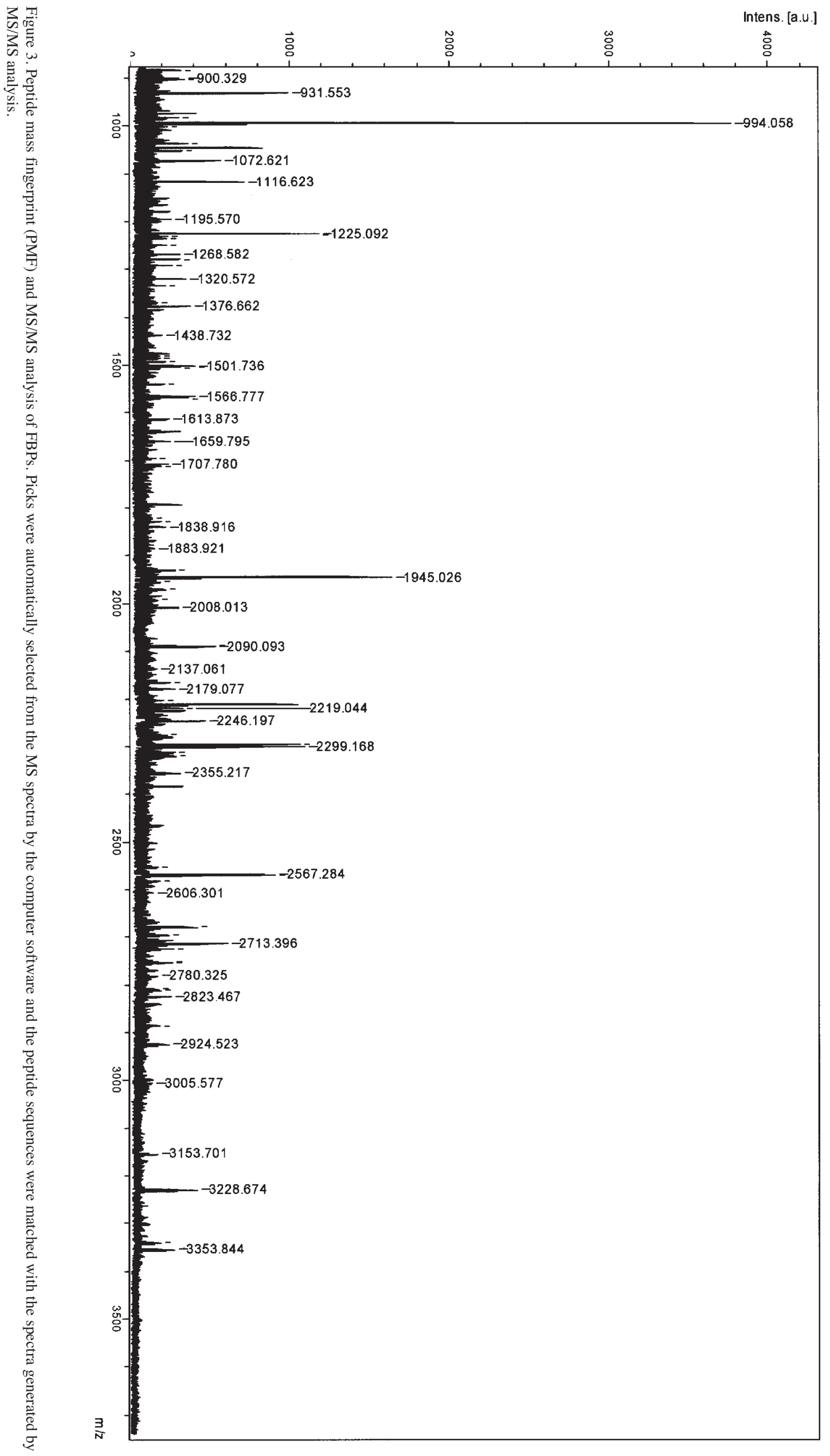


Table I. Mass spectrometrical identification of FBPs in medulloblastoma cell line (DAOY).

\begin{tabular}{|c|c|c|c|c|c|c|c|c|c|c|c|c|c|}
\hline \multirow[b]{2}{*}{ Acc. no. } & \multirow[b]{2}{*}{$\begin{array}{l}\text { Protein } \\
\text { name }\end{array}$} & \multirow[b]{2}{*}{$\begin{array}{c}\text { No. of } \\
\text { identified } \\
\text { spots }\end{array}$} & \multirow[b]{2}{*}{$\mathrm{TMW}^{\mathrm{a}}$} & \multirow[b]{2}{*}{$\mathrm{TIP}^{\mathrm{b}}$} & \multirow[b]{2}{*}{$\mathrm{OIP}^{\mathrm{c}}$} & \multicolumn{5}{|c|}{$\begin{array}{c}\text { Mascot-search results } \\
\text { (combined MS and MS/MS) }\end{array}$} & \multicolumn{3}{|c|}{ MS/MS results } \\
\hline & & & & & & $\mathrm{OMW}^{\mathrm{d}}$ & Score & $\begin{array}{l}\text { No. of } \\
\text { matched } \\
\text { peptides }\end{array}$ & $\begin{array}{c}\text { Sequence } \\
\text { coverage } \\
(\%)\end{array}$ & Expectation & Score & $\begin{array}{c}\text { Significant } \\
\text { matched } \\
\text { peptides }\end{array}$ & Peptide sequence \\
\hline \multirow[t]{5}{*}{ Q96AE4 } & Far & 2 & 67473 & 7.2 & 6.8 & 67603 & 282 & 35 & 45 & $6.6 \mathrm{e}-024$ & 118 & 2 peptides & IGGNEGIDVPIPR \\
\hline & upstream & & & & & & & & & & & & CQHAAEIITDLLR \\
\hline & element & & & & 6.9 & 67603 & 341 & 35 & 43 & $8.3 e-030$ & 174 & 3 peptides & FAVGIVIGR \\
\hline & binding & & & & & & & & & & & & IGGNEGIDVPIPR \\
\hline & protein 1 & & & & & & & & & & & & CQHAAEIITDLLR \\
\hline \multirow[t]{8}{*}{ Q92945 } & Far & 5 & 72709 & 8.0 & 6.8 & 73458 & 424 & 22 & 32 & $4.2 \mathrm{e}-038$ & 321 & 2 peptides & IINDLLQSLR \\
\hline & upstream & & & & & & & & & & & & AINQQTGAFVEISR \\
\hline & element & & & & 6.8 & 73063 & 411 & 36 & 48 & $8.3 e-037$ & 196 & 2 peptides & IINDLLQSLR \\
\hline & binding & & & & & & & & & & & & AINQQTGAFVEISR \\
\hline & protein 2 & & & & 6.7 & 73458 & 349 & 29 & 44 & $1.3 e-030$ & 178 & 2 peptides & IINDLLQSLR \\
\hline & & & & & & & & & & & & & AINQQTGAFVEISR \\
\hline & & & & & 6.6 & 73063 & 259 & 27 & 44 & $1.3 e-021$ & 88 & 1 peptide & AINQQTGAFVEISR \\
\hline & & & & & 6.9 & 73458 & 119 & 13 & 25 & $1.3 \mathrm{e}-007$ & 43 & 1 peptide & AINQQTGAFVEISR \\
\hline \multirow[t]{5}{*}{ Q96I24 } & Far & 1 & 67473 & 7.2 & 8.3 & 61944 & 139 & 18 & 48 & $2.9 \mathrm{e}-009$ & - & - & - \\
\hline & upstream & & & & & & & & & & & & \\
\hline & element & & & & & & & & & & & & \\
\hline & binding & & & & & & & & & & & & \\
\hline & protein 3 & & & & & & & & & & & & \\
\hline
\end{tabular}

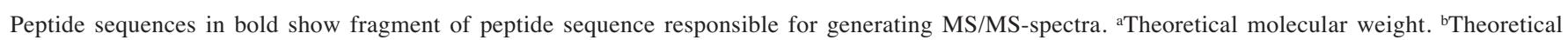
isoelectric point. ${ }^{\mathrm{c} O b s e r v e d ~ i s o e l e c t r i c ~ p o i n t . ~}{ }^{\mathrm{d} O b s e r v e d ~ m o l e c u l a r}$ weight.

MS/MS spectra of $\mathrm{m} / \mathrm{z} 931.56 \mathrm{~m} / \mathrm{z} 1336.72$ and $\mathrm{m} / \mathrm{z} 1539.80$ were significantly matched to peptide sequences of 'FAV GIVIGR', 'IGGNEGIDVPIPR' and 'CQHAAEIITDLLR', respectively (Fig. 3b). Collectively, the data confirm unambiguous assignment of the two spots to FBP1 (accession no. Q96AE4).

Not unlike FBP1, all of the five spots of FBP2 that were identified by mass spectrometry had shown significant matching following MS/MS. PMF analysis showed a sequence coverage of $32,48,44,44$ and $25 \%$ for spot FBP2a-e, respectively (Table I, Fig. 2b). The computer then picked up a list of peptides for fragmentation and for a series of tandem spectrometry. Two peaks for spot FBP2a (m/z 1184.73 and $\mathrm{m} / \mathrm{z}$ 1533.83) (Fig. 3c), spot FBP2b (m/z 1184.70 and $\mathrm{m} / \mathrm{z}$ 1533.81) (Fig. 3d) and spot FBP2c (m/z 1184.70 and $\mathrm{m} / \mathrm{z}$ $1533.81 \mathrm{~m})$ (Fig. 3e), and one for FBP2d (m/z 1533.82) (Fig. 3f) and FBP2e (m/z 1533.82) (Fig. 3g) were picked from the generated MS spectrum and found to significantly match with the peptide sequences given in Table I following MS/MS analysis (Fig. 3c-g), pointing to the unequivocal assignment of the spots to FBP2 (accession no. Q92945).

The single spot identified as FBP3 (accession no. Q96I24) by MS had a sequence coverage of $48 \%$ (Fig. 2c). Although the spectra obtained following MS analysis assigned the spot to FBP3 (Fig. 3h), the effort made to confirm by MS/MS was not successful due to several reasons.

\section{Discussion}

FBP1 was originally identified as a factor binding to FUSE, a positive cis-element of the human c-myc gene $(3,14,15)$. In addition to their transcriptional role, FBPs have been reported to bind RNA and participate in various processes of RNA processing, transport and catabolism (16). Members of the myc family of oncogenes, including N-myc, c-myc, and L-myc have been implicated in the development of many human tumors. Myc forms a heterodimer with Max and binds to E-box elements in promoter and/or enhancer regions of target genes to modulate transcription (17).

The c-myc gene encodes an important member of the helix-loop-helix leucine zipper family of transcription factors and is involved in cell growth, proliferation, differentiation and apoptosis $(1,3,14,15)$, thus its deregulation contributes to formation of a variety of tumors. Indeed, overexpression of c-myc was one of the first acquired genomic alterations found in medulloblastoma (18) and the expression of c-myc mRNA 
by the tumor correlates with poor survival, suggesting that high c-myc expression produces a more aggressive tumor phenotype (19). Although this deregulation largely results from genomic amplification of c-myc, mechanisms independent of genomic amplification have also been suggested to lead to activation of c-myc in medulloblastoma cell lines (20). Regulation of the abundance or activity of proteins binding to the c-myc gene may thus provide an essential non-genomic mechanism for controlling c-myc expression. In this regard, although there are some techniques, including immunochemistry that can be of use, a robust and reliable analytical tool is lacking. In the present study, we systematically elaborated the protein profile of the DAOY medulloblastoma cell line by a high-throughput proteomic analysis and unambiguously identified FBPs, which opens up an exciting possibility to better understanding of tumor biology.

FBP mRNA has been shown to be expressed broadly, but to varying levels, in different tissues and cell lines $(3,14)$. FBP1 protein is also detected in the HeLa cell line by immunoblotting and/or immunostaining (16,21). In our earlier study (7), FBP1 protein was detected only in D283, FBP2 in both D283 and DAOY cell lines, and FBP3 in none of the cell lines. Vindigni et al (22) purified DNA helicase V by affinity chromatography from a HeLa cell line and reported that this helicase is identical to FBP1. They showed that helicase V/FBP1 unwinds DNA with a 3 ' to $5^{\prime}$ polarity in a strictly ATP-dependent fashion, although an accumulated body of evidence indicates that FBP1 binds to single-stranded or torsionally strained DNA and is devoid of inherent unwinding activity $(1,23)$.

Here, we also detected several spots representing FBP1 and FBP2, probably indicating the existence of different splice variants, isoforms or a post-translationally modified form of the same variant. Indeed, two splice variants of FBP1 have been entered in the Swiss-Prot database (Q96AE4-1 and Q96AE4-2), although no experimental confirmation is available.

Though all the spots representing FBP1 and FBP2 produced significant MS and MS/MS results, this could not be replicated at the stage of tandem mass spectroscopy when it came to FBP3. It is well known that there are numerous sources of error associated with the collection and processing of tandem mass spectra including, but not limited to, errors attributed to the number of ion counting events (i.e., counting statistics), the inherently random nature of the fragmentation process, and errors attributed to centroiding (24). All of these sources might have contributed to the relative failure to characterize FBP3. The possibility that failure of identification by MS/MS could be attributed to low abundance of the protein cannot be totally excluded. A growing body of evidence indicates that post-translational modifications such as phosphorylation, acetylation and fatty acid modification can shift the pI to lower values and increase the molecular weight to higher values (25). It is thus plausible that such modifications could explain the shift in pI and molecular weight in all FBPs. Indeed, database search predicting possible post-translational modifications revealed that phosphorylation (http://www.cbs.dtu.dk/services/ NetPhos/) is the likely modification to occur with FBP.

The transcription of the human c-myc gene is affected by multiple cis-elements that are present both upstream and downstream of the promoter sites and a multitude of signals can affect a cell's decision to proliferate by acting through these cis-acting elements. Single-strand DNA in these ciselements is induced by torsion and flexural strain exerted on the DNA during the course of transcription (5) and the recognition of single stranded cis-elements by transcriptional regulators provides a mechanism for the re-establishment of transcription after mitosis (26) and the tight control of oncogenes $(23,27)$. FUSE, one of the cis-elements, is most active in undifferentiated cells and becomes inactive as differentiation is induced and transcription initiation is shut off $(2,14)$. FBP1 is also shown to be highly expressed in dividing cells with a temporal and regulatory profile paralleling c-myc. However, no growth-regulated or differentiation-specific expression of FBP2 and FBP3 has been observed, implicating FBP1 as a candidate for regulating cell growth and differentiation (4). The lingering expression of FBP2 and FBP3 during differentiation while that of FBP1 is shut off suggests that FBPs may have other cellular activities apart from growth regulation, such as regulation of other molecules with short half-life where small changes in expression modify cellular activity (23). Thus, a protein analytical tool that allows expression of all the FBP proteins to be detected offers a fertile ground for discerning other cellular roles of the proteins.

Proteomics is a particularly rich source of biological information because proteins are involved in almost all biological activities and they also have diverse properties, which collectively contribute greatly to our understanding of biological systems (28). The high precision of mass spectrometric measurements can distinguish closely related species, and tandem mass spectrometry or MS/MS can provide structural information on molecular ions that can be isolated and fragmented within the instrument. Detection of the variants of FBP in the DAOY cell line using MS/MS indeed confirms the robustness of this method compared to PMF and presents an opportunity, without a need for antibody availability and specificity, for unambiguous assigning of identity to proteins as well as for manipulating the protein to further our understanding of tumor biology.

\section{Acknowledgements}

We kindly acknowledge the supply of DAOY cells by Professor Michael Grotzer, University of Zürich, Switzerland. Dr Ephrem Engidawork is supported by the Austrian Embassy Development Cooperation, Addis Ababa, Ethiopia. We acknowledge contribution of the Forschungsgesellschaft für cerebrale Tumore.

\section{References}

1. Michelotti GA, Michelotti EF, Pullner A, Duncan RC, Eick D and Levens D: Multiple single-stranded cis elements are associated with activated chromatin of the human c-myc gene in vivo. Mol Cell Biol 16: 2656-2669, 1996.

2. Avigan MI, Strober B and Levens D: A far upstream element stimulates c-myc expression in undifferentiated leukemia cells. J Biol Chem 265: 18538-18545, 1990.

3. Duncan R, Bazar L, Michelotti G, Tomonaga T, Krutzsch H, Avigan M and Levens D: A sequence-specific, single-strand binding protein activates the far upstream element of c-myc and defines a new DNA-binding motif. Genes Dev 8: 465-480, 1994. 
4. Davis-Smyth T, Duncan RC, Zheng T, Michelotti G and Levens D: The far upstream element-binding proteins comprise an ancient family of single-strand DNA-binding transactivators. J Biol Chem 271: 31679-31687, 1996.

5. Duncan R, Collins I, Tomonaga T, Zheng T and Levens D: A unique transactivation sequence motif is found in the carboxylterminal domain of the single-binding-protein FBP. Mol Cell Biol 16: 2274-2282, 1996

6. Trojanowski JQ, Tohyama T and Lee VM: Medulloblastomas and related primitive neuroectodermal brain tumors of childhood recapitulate molecular milestones in the maturation of neuroblasts. Mol Chem Neuropathol 17: 121-135, 1992.

7. Peyrl A, Krapfenbauer K, Slave I, Yang JW, Strobel T and Lubec G: Protein profiles of medulloblastoma cell lines DAOY and D283: identification of tumor-related proteins and principles. Proteomics 3: 1781-1800, 2003.

8. Patterson SD and Aebersold RH: Proteomics: the first decade and beyond. Nat Genet 33: 311-323, 2003.

9. Jacobsen PF, Jenkyn DJ and Papadimitriou JM: Establishment of a human medulloblastoma cell line and its heterotransplantation into nude mice. J Neuropathol Exp Neurol 44: 472-485, 1985.

10. Bradford MM: A rapid and sensitive method for the quantitation of microgram quantities of protein utilizing the principle of protein-dye binding. Anal Biochem 72: 248-254, 1976.

11. Weitzdoerfer R, Fountoulakis M and Lubec G: Reduction of actin-related protein complex 2/3 in fetal Down syndrome brain. Biochem Biophys Res Commun 293: 836-841, 2002.

12. Yang JW, Czech T and Lubec G: Proteomic profiling of human hippocampus. Electrophoresis 25: 1169-1174, 2004.

13. Berndt P, Hobohm U and Langen H: Reliable automatic protein identification from matrix-assisted laser desorption/ionization mass spectrometric peptide fingerprints. Electrophoresis 20: 3521-3526, 1999.

14. Bazar L, Harris V, Sunitha I, Hartmann D and Avigan M: A transactivator of c-myc is coordinately regulated with the protooncogene during cellular growth. Oncogene 10: 2229-2238, 1995.

15. Bazar L, Meighen D, Harris V, Duncan R, Levens D and Avigan M: Targeted melting and binding of a DNA regulatory element by a transactivator of c-myc. J Biol Chem 270: 8241-8248, 1995.

16. Sully G, Dean JL, Wait R, Rawlinson L, Santalucia T, Saklatvala J and Clark AR: Structural and functional dissection of a conserved destabilizing element of cyclo-oxygenase-2 mRNA: evidence against the involvement of AUF-1 [AU-rich element/ poly(U)-binding/degradation factor-1], AUF-2, tristetraprolin, HuR (Hu antigen R) or FBP1 (far- upstream-sequence-elementbinding protein-1). Biochem J 377: 629-639, 2004.
17. Raetz EA, Kim MK, Moos P, Carlson M, Bruggers C, Hooper DK, Foot L, Liu T, Seeger R and Carroll WL: Identification of genes that are regulated transcriptionally by Myc in childhood tumors. Cancer 98: 841-853, 2003.

18. Bigner SH, Friedman HS, Vogelstein B, Oakes WJ and Bigner DD: Amplification of the c-myc gene in human medulloblastoma cell lines and xenografts. Cancer Res 50: 2347-2350, 1990.

19. Herms J, Neidt I, Luscher B, Sommer A, Schurmann P, Schroder T, Bergmann M, Wilken B, Probst-Cousin S, HernaizDriever P, Behnke J, Hanefeld F, Pietsch T and Kretzschmar HA: $\mathrm{C}-\mathrm{Myc}$ expression in medulloblastoma and its prognostic value. Int J Cancer 89: 395-402, 2000.

20. Siu IM, Lal A, Blankenship JR, Aldosari N and Riggins GJ: C-Myc promoter activation in medulloblastoma. Cancer Res 63: 4773-4776, 2003

21. He L, Weber A and Levens D: Nuclear targeting determinants of the far upstream element binding protein, a c-myc transcription factor. Nucleic Acids Res 28: 4558-4565, 2000.

22. Vindigni A, Ochem A, Triolo G and Falaschi A: Identification of the human DNA helicase V with the far upstream elementbinding protein. Nucleic Acids Res 29: 1061-1067, 2001.

23. He L, Liu J, Collins I, Sanford S, O'Connell B, Benham CJ and Levens D: Loss of FBP function arrests cellular proliferation and extinguishes c-myc expression. EMBO J 19: 1034-1044, 2000.

24. Venable JD and Yates JR III: Impact of ion trap tandem mass spectra variability on the identification of peptides. Anal Chem 76: 2928-2937, 2004.

25. Mann M and Jensen ON: Proteomic analysis of post-translational modifications. Nat Biotechnol 21: 255-261, 2003.

26. Michelotti EF, Sanford S, Freije JM, MacDonald NJ, Steeg PS and Levens D: Nm23/PuF does not directly stimulate transcription through the CT element in vivo. J Biol Chem 272: 22526-22530, 1997.

27. Liu J, Akoulitchev S, Weber A, Ge H, Chuikov S, Libutti D, Wang XW, Conaway JW, Harris CC, Conaway RC, Reinberg D and Levens D: Defective interplay of activators and repressors with TFIH in xeroderma pigmentosum. Cell 104: 353-363, 2001.

28. Fountoulakis M: Proteomics: current technologies and applications in neurological disorders and toxicology. Amino Acids 21: 363-381, 2001. 